\title{
DAMPAK PENERBITAN DAN PENJUALAN SURAT UTANG NEGARA (SUN) BAGI PEREKONOMIAN INDONESIA
}

\author{
Irma Setyawati \\ STIMA KOSGORO
}

\begin{abstract}
The edition and the sale of the country's obligation letter (SUN) give the impact to the benking sector, monetery, and fiscal, as well as the monitory authority. The objective of the study is to verify the impact of the edition and the sale of the SUN for indonesian economy. The methods used are descriptive analysis of the collected date from library research and other resources related to the topic. The research found that (1) the impact to the Cepital Adequecy Ratio (SAR) is getting better. (2) the impact to the monetary is the increase of the money quantity as much as the interest payment given by the government conserving the SUN property. (3) the impact to the monetary authority is the decrease of liquidity support and the increase of Indonesian Bank outstanding to the govemment. The sale of SUN gives fresh fund to the government which can be invested, to the productivity asset, fo support the process of economy recovery.
\end{abstract}

\section{PENDAHULUAN}

Dalam sejarah dunia perbankan di Indonesia, tahun 1997 merupakan saat dan kondisi yang terburuk karena pada pertengahan tahun tersebut terjadi penurunan nilkai ruplah terhadap mata uang asing yang membawa pengaruh secara signifikan terhadap perkembangan kondisi perekonomian di Indonesia dan perbankan secara keseluruhan. Berbagai fenomena terjadi antar lain: (1) timbulnya krisis kepercayaan masyarakat terhadap bank, (2) dalikuldasinya beberapa bank karena tingginya tingkat suku bunga simpanan bank pada saatitu yaitu mencapai $65.70 \%$ per tahun yang tentunya tidak diperlakukan sama dalam pemberian kredit sehingga mengakibatkan terjadinya negative spreads, dan tingginya jumlah pinjaman dalam valuta asing yang dimiliki oleh perbankan nasional karena akses yang cukup tinggi ke pasar internasional.

Peristiwa buruk yang menimpa dunia perbankan tersebut berimbas hingga saat ini. Dalam kondisi perekonomian yang bergejolak, hanya bank-bank yang sehat saja yang mampu bertahan sementara bank-bank yang rapuh dipastikan akan jatuh. Menanggapi hal ini pemerintah berusaha sekuat tenaga untuk menyelamatkan dunia perbankan yang sebagian besar sudah berada pada kondisi yang mengkhawatirkan. Hal ini karena perbankan bagaikan jantung perekonomian nasional. Apabila perbankan hancur, maka kondisi perekonomian dapat dipastikan akan semakin bergejolak.

Salah satu dari program yang ditetapkan oleh pemerintah tersebut adalah program rekapitalisasi perbankan yang bertujuan untuk mempertahankan keberadaan bank-bank yang mempunyai prospek untuk hidup dan terus berkembang. Untuk itu pemerintah menerbitkan Surat Utang Negara (SUN), secara bertahap mulai bulan September 1998 sampai dengan Oktober 2000 . Untuk memperkuat legalitas atas penerbitan SUN, pada tahun 2002 pemerintah telah menerbitkan UndangUndang No. 24 tahun 2002 tentang SUN.

Selain itu, untuk mengembangkan pasar SUN tidak hanya berdasarkan kebijakan yang diterapkan tetapi juga tidak terlepas dari sarana infrastruktur yang digunakan baik untuk transaksi perdagangan maupun sarana settle. ment. Hal ini dilakukan baik untuk mengurangi risiko yang timbul karena terjadinya kegagalan sistem (settlement risk) tetapi juga untuk lebih mengefisienkan waktu dan biaya dalam rangka pelaksanaan transaksi tersebut.

Sehubungan dengan hal tersebut di atas, maka dibutuhkan suatu strategi yang yang tepat untuk mendukung pengembangan pasar sekunder SUN, Strategi ini disusun berdasarkan beberapa aspek yaitu pemerintah selaku penerbit, kemudian Bank Indonesia selaku otoritas kebijakan moneter dan pelaku pasar sebagai pihak yang terlibat langsung dalam aktivitas transaksi SUN di pasar sekunder, sehingga penerbitan dan penjualan SUN berdampak postif bagi perekonomian Indonesia, dan pada hal-hal lainnya seperti pada sektor perbankan, otoritas moneter dsan fiskal.

Tujuan dari penulisan makalah ini untuk mengetahui Impak penerbitan dan penjualan SUN tersebut terhadap sektor perbankan, moneter dan fiskal.

\section{PEMBAHASAN}

SUN merupakan surat berharga berupa surat pengakuan utang dalam mata uang rupiah maupun valuta asing yang dijamin pembayaran bunga dan pokok oleh 
negara Republik Indonesia, sesuai dengan masa berlakunya (sebagaimana dimaksud dalam UU RI No. 24 Tahun 2002 tentang Surat Utang Negara Pasal 1 Ayat 1).

Pada awalnya SUN diterbitkan untuk menyelamatkan sistem perbankan pada saat terjadinya krisis ekonomi Indonesia pada pertengahan tahun 1997. SUN sebagai pengganti SBI (Sertifikat Bank Indonesia) yang selama ini dipakai oleh Bank Indonesia dalam pengendallan moneter menunjukkan prospek yang cukup baik. Hal ini disebabkan oleh beberapa keunggulan yang dimitiki oleh SUN di antaranya adalah :

1. SUN merupakan surat utang yang diterbitkan olah pemerintah, sehingga beban bunga atau kupon yang ditimbulkan akibat penerbitan SUN seluruhnya menjad: tanggungan pemerintah, bukan merupakan beban Bank Indonesia. Hal ini dapat mengurangi tekanan pada sisi pengeluaran yang selama ini ditanggung oleh Bank Indonesia atau akan terjadi shifting pembiayaan instrumen kebijakan moneter dari Bank Indonesia ke pemerintah melalui pembayaran bunga SUN oleh pemerintah.

2. Pada situasi perekonomian yang normal, tingkat suku bunga SUN diupayakan untuk lebih kecil dibandingkan dengan tingkat suku bunga pasar. Dana yang ditanamkan dalam bentuk SUN dengan kondisi ini merupakan kelebihan dana yang tidak dapat diserap oleh pasar, sehingga dana yang masuk benar-benar merupakan kelebihan yang jika tidak ditanamkan dalam bentuk SUN akan merupakan idle money. (Budilaksono 2004)

Dengan pilihan jangka waktu maturity yang lebih panjang, setelah SUN jatuh tempo dapat dilakukan refinancing atau mengeluarkan SUN dengan jangka waktu yang lebih panjang, hingga jangka waktu maksimum. Hal ini sejalan bahwa pembiayaan jangka pendek atau jangka panjang akan lebih aman jika dibiayai oleh pinjaman jangka panjang.

Pihak-pihak yang memiliki otoritas atau kewenangan atas SUN, adalah:

1. Bank Indonesia, memiliki beberapa tugas atau fungsi, antara lain:

a. Sebagai agen lelang SUN, Bank Indonesia membantu pemerintah melakukan seleksi peserta lelang SUN di pasar perdana, sesuai kriteria dan persyaratan yang ditetapkan oleh Menteri Keuangan.

b. Sebagai penatausaha SUN, Bank Indonesia melakukan kegiatan yang mencakup kliring, settlement, dan pencatatan kepemilikan, serta agen pembayaran bunga dan pokok SUN saat jatuh waktu.

c. Sebagai pemberi masukan pada Menteri Keuangan. masukan ini bertujuan untuk mengevaluasi implikasi moneter dalam penerbitan SUN agar keselarasan dalam kebijakan fiskal termasuk manajemen utang pemerintah dan kebiakan moneter dapat tercapai.

d. Departemen Keuangan, tugas dan fungsinya disesuaikan dengan bagian yang terkait, karena di Departemen Keuangan terdapat 2 (dua) bagian, yaitu (1) Direktorat Pengelolaan SUN (DPSUN), mempunyai kewenangan dalam penerbitan dan pengelolaan SUN, (2) Bapepam, mempunyai keweriangan untuk mengatur dan mengawasi transaksi perdagangan SUN di pasar sekunder.

Dari berbagai surat utang yang diterbitkan oleh pemerintah tersebut, SUN yang dapat diperdagangkan di pasar sakunder terdiri dari seri seri Fixed Rate (FR) dan Variabel Rate (VR), serta seri Hedge Bond ( $\mathrm{HB}$ ) yang yang sebagian besar pelunasannya dilakukan refinancing dengan melalui reopening seri VR yang sudah ada.

FR diterbitkan untuk meningkatkan Capital Adequancy Ratio (CAR) bank dari $0 \%$ menjadi $4 \%$, yang terdiri dari 5 (lima) seriFR, antara lain FRC001 - FR0005 dengan jangka waktu 5- 10 tahun. Dalam rangka mendorong transaksi pasar sekunder pada bulan Desember 2000 dilakukan pertukaran sebagian seri FR0001 dan FRO003 dengan tingkat kupon masing-masing 12,0\% dengan seri FR0006 - FR0009 dengan tingkat kupon $10,0 \%-16,5 \%$ yang dikenal dengan program bonds exchange offer atau stappied bonds.

Selanjutrya, dalam rangka reprofiling, pada bulan November 2002 pemerintah meserbitkan seri FRO010 FR0020 yang berjangka waktu 8 - 11 tahun untuk menggantikan seri-seri dengan sisa jangka waktu 2 - 7 tahun.

VR diterbitkan untuk mengembalikan CAR perbankan yang negatif menjadi $0 \%$, yang terdiri dari 16 seri, antara lain VR001 - VRO016 dengan jangka waktu 3 - 10 tahun. VR0001 - VR0003 telah jatuh tempo masing-masing pada tanggal 25 Juli 2002, 25 Februati 2003, 25 Juni 2003. Pada tahun 2004, seri yang jatult tempo adalah VR0004 - VR0006 masing-masing pada 25 Januari 2004, 25 Mei 2004 , dan 25 Desember 2004. Seri VR0017 dan VR0018 diterbitkan kemudian dalam rangka konversi atau pelunasan seri HB. Dalam rangka reprofilling pemerintah menerbitkan seri VR0019 - VR0031 yang berjangka waktu 12- 18 tahun untuk menggantikan seri-seri dengan sisa jangka waktu 1.7 tahun.

HB diterbitkan untuk menjaga Net Open Position (NOP) bank. Nilai nominal obligasi dikaitkan (diindeks) terhadap nilai tukar rupiah. Apabila nilai tukar rupiah terhadap USD melemah, nilai nominal HB setelah indeksasi akan meningkat, vice versa. Seri HB diterbitkan dengan jangka waktu 1 - 2 tahun, dengan tingkat bunga kupon 
mengambang SIBOR 3 bulan $+2 \%$, yang pada akhir tahun 2003 adalah sebesar $3,17 \%$. Berbeda dengan seri FR dan VR, seri HB tidak dapat diperdagangkan di pasar sekunder. Saat ini sudah tidak ada lagi seri HB yang masih beredar, karena semua serinya sudah dilunasi,

Seperti SBI dan SBPU (Surat Berharga Pasar Uang). SUN dapat diperdagangkan pada 2 (dua) pasar, yaitu;

\section{Primary market (pasar perdana)}

a. Perdagangan saat pertama kali SUN diterbitkan,

b. Pubjic Expose (tanggal penawaran, penjatahan, pembayaran, penyerahan SUN).

c. Harga ; discount/par,

d. Investor hanya membayar sebesar harga beli.

\section{Secondary market (pasar sekunder)}

a. Pasar yang memperdagangkan SUN yang telah diperdagangkan di pasar primer,

b. Harga: discount/parforemium,

c. Investor membayar: Harga beli + accrued interest (bila pembelian secara outright).

d. Investor menerima: Harga jual + accrued interest (bila pembelian secara outright).

Sebelum lock up SUN pemerintah dibuka tanggal 1 Februari 2000 , bank diperbolehkan untuk mengagunkan maksimal $10 \%$ dari SUN pemerintah yang dimilikinya kepada pihak ketiga baik bank, non-bank, domestik, asing maupun kepada Bank Indonesia, dengan tujuan sebagai berikut:

1. Untuk mengatasi kesulitan likuiditas, sesuai dengan $\mathrm{PBI}$ No.1/10/PBI/1999 Pasal 9 SUN dapat diagunkan kepada pihak ketiga.

2. Untuk mengatasi pendanaan jangka pendek dalam menghadapi MKT 2000, sesuai dengan PBI No.1/11/PBI/ 1999 Pasal 8 : SUN dapat diagunkan kepada BI dengan nilai $75 \%$ dari nilai nominal SUN dan tingkat diskonto sebesar $125 \%$ suku bunga SBI 1 bulan pada lelang terakhir.

Adapun akibat-akibat pengagunan kepada phak ketiga adalah sebagai berikut:

1. Pengagunan kepada bank domestik tidak akan berdampak moneter,

2. Pengagunan kepada pihak non-bank domestik akan berakibat berkurangnya Net Claim to Govemment dan M2 sebesar maksimal 10\% SUN rekapitalisasi,

3. Pengagunan kepada bank yang ada di luar negeri akan mengakibatkan meningkatnya Net Foreign Assets (NFA) dan giro bank (Mo) sebesar maksimal 10\% SUN rekapitalisasi. Dampak selanjutnya terhadap perekonomian dan moneter adalah peningkatan $\mathrm{M} 2$ akibat proses multiplier,

4. Pengagunan kepada pihak asing non-bank berdampak sama dengan pengagunan bank yang ada di luar negeri.
Sedangkan pengagunan kepada Bank Indonesia maksimal berjumlah $75 \%$ dari nitai nominal SUN rekapitalisasi dan hat tersebut berdampak pada peningkatan uang primer sebesar maksimal $75 \%$ nilai nominal SUN rekapitalisasi dikurangi tingkat diskonto. Secara umum, pengagunan tersebut memang hanya ditujukan untuk membantu pengelolaan likuiditas bank dalam jangka waktu pendek. Hal tersebut dapat dilihat dari masa berlakunya pengagunan kepada pihak ketiga adalah 3 Desember 1999 sampai dengan 31 Januari 2000 dan pengagunan kepada Bank Indonesia adalah 22 Desember 1999 sampai dengan 17 Januari 2000 dalam rangka MKT 2000, Untuk mengetahui efektivitas SUN sebagai salah satu piranti kebịakan moneter, maka harus diketahui dampak positif dan negatif dari penerbitan dan penjualan SUN.

\section{Dampak Penerbitan SUN}

SUN pertama kali diterbitkan pemerintah pada tahun 2000. Penerbitan SUN mempunyai dampak terhadap sektor perbankan, moneter dan fiskal serta otoritas moneter.

\section{Sektor Perbankan}

Dampak terhadap perbankan bahwa penerbitan SUN telah membuat permodalan (CAR) bank membaik, sehingga diharapkan bank dapat melakukan penyaluran kredit ke sektor riil. Seperti terlihat pada tabel 1, CAR 5 (lima) bank di Indonesia, yang terdiri dari 2 (dua) bank milik pemerintah dan 3 (tiga) bank swasta nasional, menunjukkan modal kelima bank tersebut di atas dari permodalan yang ditetapkan Bank Indonesia, yaitu $8 \%$ dari ATMR (Aktiva Tertimbang Menurut Risiko), Terlihat pada tabel 1 sebagai berikut:

\begin{tabular}{llllllll}
\hline No & Nama & 2000 & 2001 & 2002 & 2003 & 2004 & 2005 \\
\hline 1 & $\begin{array}{l}\text { Bank } \\
\text { Mandin }\end{array}$ & $31 \%$ & $26 \%$ & $23 \%$ & $27 \%$ & $25 \%$ & $23 \%$ \\
\hline 2 & BCA & $33 \%$ & $32 \%$ & $32 \%$ & $27 \%$ & $23 \%$ & $21 \%$ \\
\hline 3 & BNi & $13 \%$ & $14 \%$ & $15 \%$ & $18 \%$ & $17 \%$ & $16 \%$ \\
\hline 4 & $\begin{array}{l}\text { Bank } \\
\text { Permata }\end{array}$ & $13 \%$ & $8 \%$ & $10 \%$ & $10 \%$ & $11 \%$ & $9 \%$ \\
\hline 5 & $\begin{array}{l}\text { Bank } \\
\text { Niaga }\end{array}$ & $21 \%$ & $16 \%$ & $12 \%$ & $11 \%$ & $10 \%$ & $17 \%$ \\
\hline
\end{tabular}

Sumber : Bank Indonesia (2005) data diolah

Di antara kelima bank tersebut, pada tahun 2005, Bank Mandiri memiliki CAR yang tertinggi. Di samping itu, pendapatan bunga SUN yang diterima perbankan telah meningkatkan pendapatan perbankan (rentabilitas) dan menambah likuiditas karena menerima dana segar. Dengan penerbitan SUN rekapitalisasi neraca bank juga terlihat membaik, karena adanya tambahan modal pada 
sisi pasiva dan SUN (tag han bank pada pemerintah) pada sisi aktiva (Dewanti.2004). Namun, mengingat penyertaan modal pemerintah hanya berupa penerbitan surat berharga (obligasi/SUN) dan bukan dana segar, maka tidak ada tambahan llkuiditas yang berarti bagi bank untuk dapat disalurkan ke sektor riil. Selanjutya, tambahan likuiditas bagi bank baru terjadi pada saat menerima kupon SUN. Jumlah SUN yang dimiliki oleh sektor perbankan di Indo. nesia.

Kepemilikan SUN terdiri dari perbankan dan non perbankan. Sektor perbankan terdiri dari bank rekap dan bank non rekap, sedangkan sektor non perbankan terdiri dari penduduk (reksadana, asuransi, lembaga pembiayaan, dana pensiun, sekuritas, perusahaan dan lain-lain) serta non penduduk (lembaga keuangan dan lainIain), Komposisi kepemilikan SUN secara lengkap disajikan pada tabel 2.

Tabel 2. Komposisi Kepemilikan SUN (miliar rupiah)

\begin{tabular}{|c|c|c|c|c|c|c|}
\hline & 2000 & 2001 & 2002 & 2503 & 2004 & 2006 \\
\hline Derrtanarkian Xenpemikian & $431,000, t 6$ & $43 n$ agzes & $419,355.39$ & 100,40050 & $402 \cos 39$ & 410,12432 \\
\hline A Porgonikm & $424.978,30$ & 472 ens 38 & $322.74+63$ & 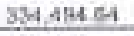 & 290349.22 & 288.35248 \\
\hline 1. Bunk Fockap & $423,103,30$ & 95e.6308: & $x$ sear2.46 & 907.04406 & $257 \times 2768$ & $251.3193 ?$ \\
\hline 2. Burk Noncevap & c gog,$x$ & 24.772 .57 & 13829.23 & $27,450,60$ & 33.00553 & $37,039.10$ \\
\hline a. Stonogivery & 1.nzans & 13.022 .02 & 44.72015 & $88,05+.92$ & 111.740 .17 & $37: 77184$ \\
\hline 1. Residen & na. & $n \rightarrow$ & $43,854.87$ & $63,367,09$ & 100.90307 & 106.190 .40 \\
\hline n Rmana Dora & na. & n. & 35,71991 & $4: 3768 \mathrm{~B}$ & $\$ 3.400 .01$ & 53359.17 \\
\hline D Astarons: & $n=$ & no & $8.5+2.79$ & 15.684 .35 & 27.006 .58 & 28.69820. \\
\hline c. Nerbarikin & $n=$ & n.u. & 1.08650 & 597.58 & 701.40 & $1.1655 t$ \\
\hline is Cona Fernaiun & $n \geq$. & na & $360<1$ & 3.220 .16 & 17.121 .36 & $18.117 \mathrm{es}$ \\
\hline e Senuntas & n-a. & na & 133.60 & 29400 & 502.60 & 242.50 \\
\hline EPrusuatan & $n \pi$ & na & 61.85 & 164.75 & 518.30 & 490.64 \\
\hline Q. Gain-bun & It.a. & na & 200 & 4055 & 1.852 .71 & 1,69472 \\
\hline 2. Niprevesiage & ก. & na & 927.28 & $504 \pi 3$ & 10.747 .10 & 16.575 .4 \\
\hline alumbaga seuanger. & na. & no. & \$43.89 & 5.549 .00 & to.65.4. 43 & $16.4 \div 894$ \\
\hline b. Lumtya & n.a. & ne. & 0206 & 3500 & 112.57 & 128.50 \\
\hline C. Departumen Kevampon & & 877.65 & 1872.56 & & & \\
\hline
\end{tabular}

Sumber : Bank Indonesla (2005) data diclah

Bank rekap masih menjadi kelompok pemilik terbesar SUN dengan jumlah Rp 289, 5 triliun pada tahun 2005 atau sekitar $74,4 \%$ dari total SUN. Seri SUN yang dimiliki oleh Bank Rekap sebagian besar adalah seri VR dengan porsi $74 \%$. Berdasarkan portofolionya, $70 \%$ SUN berada di portofolio investasi dan sisanya di portofolio perdagangan.

Setelah sektor perbankan, kepemilikan terbesar berikutnya pada tahun 2005 adalah reksa dana dengan posisi Rp 53,4 triliun ( $13 \%$ ), disusul bank nonrekap Rp 37,1 triliun $(9 \%)$, asuransi $R p 28,7$ triliun $(7 \%)$, dan dana pensiun Rp $19,1(4,7 \%)$ serta non residen Rp 16,8 triliun $(4 \%)$. Kepemilikan perusahaan sekuritas, yang memang berfungsi sebagai perantara di pasar, hanya sebesar Rp 242,5 miliar. Jumlah itu masih di bawah kepemilikan SUN oleh korporasi sebesar Rp 690,7 miliar.

Secara keseluruhan, kepemilikan SUN kelornpok investor mengalami kenaikan posisi kepemilikan kecuali bank nonrekap. Jumlah kenaikan terbesar dipegang oleh nonresiden sebesar Rp 5,8 triliun, disusul oleh dana pensiun sebesar Rp 1,9 triliun dan asuransi Rp 1,7 triliun,

\section{Sektor Moneter dan Fiskal}

Dari sisi moneter adanya pembayaran bunga SUN berdampak pada penambahan uang primer (Mo) sebesar nilai pembayaran bunga SUN tersebut. Semakin meningkatnya beban pembayaran SUN, akan menyebabkan ekspansi moneter (peningkatan Mo) yang semakin besar. Jika Bank Indonesia konsisten dengan target base money, maka meningkatnya ekspansi moneter akibat pembayaran bunga SUN harus diimbangi dengan peningkatan target lelang SBI (kontraksi moneter). Hal ini berarti akan $\mathrm{s}$ e $\mathrm{m}$ a $k$ in menambah outstanding SBI dan pada akhirnya akan meningkatkan biaya operasipasar terbuka. ( Laksmono R.2004) Jumlah vang beredar yang terdiri dari Mo, $M_{3}$ dan $\mathrm{M}_{2}$. dari tahun 2000 2005, sebagai terlihat pada tabel 3 berikut.
Tabel 3. Jumlah Uang Beredar (millar rupiah)

\begin{tabular}{cccc}
\hline Tahun & Mo & M) & $M_{2}$ \\
\hline 2000 & 72.371 & 162.186 & 747.028 \\
\hline 2001 & 76.342 & 177.731 & 844.053 \\
\hline 2002 & 86.696 & 191.839 & 883.808 \\
\hline 2003 & 94.542 & 223.789 & 955.692 \\
\hline 2004 & 108.265 & 253.818 & 1.033 .527 \\
\hline 2005 & 124.316 & 281.905 & 1.203215 \\
\hline
\end{tabular}

Sumber : Bank Indonesia, (2005) data diolah

Dengan adanya pembayaran bunga SUN mempengaruhi penambahan jumlah uang beredar sebesar bunga yang dibayarkan tersebut, maka dapat 
dibandingkan kontribusi pembayaran bunga SUN terhadap jumlah uang beredar. Dilihat dari sisi fișkal, jumlah anggaran pembayaran bunga pada 2000 sebesar Rp 37,46 triliun atau $2,7 \%$ dari Produk Domestik Bruto yang diterima indonesia. Pembayaran bunga SUN dialokasikan dari Anggaran Pendapatan dan Belanja Negara. Hal ini berarti pemerintah harus menyisihkan sebagian pendapatan yang diterima untuk membayar bunga SUN.

Pembayaran bunga atas SUN tersebut tidak akan memberikan dampak terhadap besaran base money. karena hanya akan terjadi perpindahan dana dari rekening pemerintah ke sisi pendapatan Bank Indonesia, sehingga tidak terjadi aliran dana ke luar dari otoritas moneter. Pembayaran bunga SUN, hanya akan memberikan dampak terhadap sisi fiskal, yaitu meningkatnya tagihan Bank Indonesia kepada pemerintah (kewajiban pemerintah kepada Bank Indonesia).

\section{Otoritas Moneter}

Pada neraca otoritas moneter, penerbitan SUN hanya berdampak terhadap berkurangnya liquidity support dan bertambahnya tagihan Bank Indonesia terhadap pemerintah. Sedangkan pembayaran bunga kepada BI menyebabkan berkurangnya rekening pemerintah atau meningkatnya Net Claim to Government (NCG) dan berkurangnya Net Other ltems (NOI).

Di lain pihak, SUN yang tidak marketable tersebut berakibat berkurangnya potensi SUN untuk dapat digunakan sebagai alternatif instrumen pengendali moneter. Baru pada bulan Agustus 2000, pembayaran bunga SUN dihitung berdasarkan besarnya inflasi (indexed). Walaupun hal ini belum ada kesepakatan antara Depatemen Keuangan dengan Bank Indonesia, namun tetap dilaksanakan setelah mendapat persetujuan Badan Pemeriksa Keuangan. Sebelumnya, pembayaran bunga SUN masih dihitung atas dasar pokok yang belum diindeks dengan inflasi (belum terdapat kesepakatan antara BI dan Depkeu mengenai besamya inflasi dan waktu pokok SUN diindeks). Jika kupon SUN tersebut dianggap sebagal penerimaan bunga dan bunga SBI (kurang lebih 12\%) dianggap sebagai biaya bunga, maka hal tersebut merupakan negative spread yang dapat menimbulkan kerugian pada neraca Bank Indonesia.

\section{Dampak Penjualan SUN}

Dengan dikeluarkannya PBI No. 1/10/PBI/1999 tanggal 3 Desember 1999, maka mulai 1 Februarl 2000 bank dimungkinkan menjual SUN maksimal sebesar $10 \%$ dari jumlah SUN yang dimiliki. Penjualan tersebut mempunyai dampak positif dan negatif terhadap bank, pasar keuangan, dan pengendalian moneter. Dampak positif dari penjualan SUN adalah sebagai berikut:
1. Penjualan SUN pemerintah oleh bank umum akan memberikan dana segar, sehingga tersedia dana untuk ditanamkan dalam aktiva produktif guna mendukung proses pemulihan ekonomi.

2. Dalam pasar keuangan, SUN pemerintah dapat berfungsi sebagal acuan suku bunga (benchmark), meningkatkan ketersedian instrumen jangka panjang. meningkatkan likuiditas pasar sekunder, meningkatkan kredibilitas pasar SUN, karena hal ini merupakan SUN pemerintah yang pertama dan selanjutnya pricing SUN ini dapat menjadi acuan kinerja bagi manajer investasi. 3. SUN pemerintah dapat digunakan sebagai salah satu alternatif instrument moneter dalam pasar terbuka selain SBI, sehingga diharapkan nantinya obligasi ini akan dapat menggantikan peran $\mathrm{SB}$, selain akan mengurangi beban Bank Indonesia juga diharapkan dapat membantu pemerintah dalam mengelola manajemen utang domestik untuk memenuhi defisit fiskalnya.

Sedangkan dampak negatif dari penjualan SUN adalah sebagai berikut:

1. Terhadap bank umum, penjualan SUN apabila tidak dilakukan dengan hati-hati dan tidak dengan perencanaan penggunaan yang tepat dapat menurunkan CAR, sehingga menimbulikan moral hazard.

2. Terhadap pasar keuangan, dalam jangka waktu pendek penjualan SUN akan mengganggu keseimbangan pasar, sehingga likuiditas pasar keuangan sementara akan terganggu sampai terbentuknya equillibrum baru. Penjualan SUN pemerintah yang bebas resiko dapat menyebabkan terjadinya perpindahan investor dari SUN perusahaan yang selama ini telah ada, apabila terdapat retum yang seimbang. Selain itu, kemungkinan lain adalah terjadinya perpindahan dana-dana jangka panjang yang selama ini tertanam di pasar uang atau dalam bentuk simpanan perbankan.

3. Dampak penjualan SUN terhadap besaran moneter sama dengan dampak penggunaan SUN tersebut kepada pihak ketiga, seperti yang telah diuralikan sebelumnya. Jika yang melakukan pembelian adalah BI dan pihak asing, maka akan terjadi ekspansi moneter. Hal ini perlu disesuaikan dengan target indikatif base money yang disepakati dengan IMF.

4. Peranan BI dalam pasar skunder SUN pemerintah adalah sebagai registrasi sentral, agen pembayar, pengembangan pasar, penunjukan market maker, dan beberapa peran lainnya. Dalam pasar sekunder BI tidak berperan sebagai underwriter, yang berarti tidak ada kewajiban bagi Bl untuk membeli SUN tersebut di pasar sekunder.

SUN dapat dibeli oleh domestik maupun asing, baik bank maupun non-bank, sehingga tidak terdapat batasan- 
batasan yang akan menghambat para investor asing untuk membelinya.

Apabila SUN dibeli oleh domestik tidak akan mempengaruhi neraca sistem moneter, maupun neraca otoritas moneter, yang terjadi adalah perpindahan dana atau likuiditas dari bank penjual kepada bank pembeli Apabila animo permintaan pembelian asing pada SUN pemerintah cukup tinggi, maka kepemilikan SUN oleh asing akan berdampak positif, tetapi juga tidak terlepas dari dampak negatif.

Dampak positifnya adalah sebagai berikut:

1. Capital infliow pada saat asing membeli, berdasarkan informasi dari bank umum, pada saat investor asing membeli SEI dilakukan dengan cara mentransfer dana valas ke Indonesia, kemudian menukarkannya ke rupiah guna membeli SBI.

2. Memperkuat kurs rupiah.

3. Membuat pasar lebih likuid karena memperbanyak peserta pasar.

4. Harga yang lebih baik, karena permintaan bertambah (discount kemungkinan menjadi lebih kecil).

5. Dapat menciptakan harga atau benchmark terhadap suku bunga jangka panjang.

Sedangkan dampak negatifnya adalah sebagai berikut: 1. Capital outflow pada saat asing menjual SUN dan membawa dananya keluar negeri

2. Ketidakstabilan kurs rupiah apabila investor asing melakukan hit and run, karena UU No.24/1999 tentang Lalu-Lintas Devisa dan Sistem Nilai Tukar yang ada tidak membatasi perpindahan devisa dan hanya bersifat monitoring, sehingga votalitas pada capital flow dan kurs belum dapat dihindari.

3. Apabila akan diterapkan pembatasan terhadap lalulintas devisa akan men-discourage investor asing dan bertentangan dengan sistem devisa sesuai UU No.24 tahun 1999 dan peraturan pasar modal. Pembatasan tersebut misalnya, kepemilikan oleh asing minimal 6 (enam) bulan dan kepemilikan oleh asing dibatasi sampai dengan presentase tertentu.

\section{PENUTUP}

\section{Kesimpulan}

1. Penggunaan SUN pemerintah sebagai pengganti SBI yang selama inl dipakai oleh Bank Indonesia dalam pengendalian moneter menunjukkan prospek yang cukup baik,

2. Penerbitan SUN berdampak terhadap perbankan, moneter dan fiskal serta neraca otoritas moneter. Dampak terhadap perbankan adalah semakin baiknya Caphtal Adequacy Ratio (CAR), terbukti dari CAR yang dimiliki 5 (lima) bank di atas $8 \%$ dari ATMR (Aktiva Tertimbang Menurut Risiko), yang merupakan ketentuan dari Bank Indonesia,

3. Dampak terhadap moneter adalah penambahan jumlah uang beredar sebesar pembayaran bunga yang diberikan pemerintah atas kepemilikan SUN. Hal tersebut didukung kepemilikan SUN sebagian besar terdapat di sektor perbankan. Sedang dampak terhadap fiskal adalah beban bunga yang ditanggung oleh pemerintah yang dibebankan padaAPBN,

4. Pada neraca otoritas moneter, penerbitan SUN hanya bardampak terhadap berkurangnya liquidity support dan bertambahnya tagihan Bank Indonesia terhadap pemerintah. Sedangkan pembayaran bunga kepada BI menyebabkan berkurangnya rekening pemerintah atau meningkatnya Net Claim to Government (NCG) dan berkurangnya Net Other llems (NOI).

5. Penjualan SUN memberikan dampak memberikan dana segar bagi pemerintah, sehingga tersedia dana untuk ditanamkan dalam aktiva produktif guna mendukung proses pemulihan ekonomi,

6. Dalam pasar keuangan, SUN pemerintah dapat berfungsi sebagai acuan suku bunga (benchmark). meningkatkan ketersedian instrumen jangka panjang. meningkatkan likuiditas pasar sekunder, meningkatkan kredibilitas pasar SUN, karena hal ini merupakan SUN pemerintah yang pertama dan selanjutnya pricing SUN ini dapat menjadi acuan kinerja bagi manajer investasi.

\section{Saran-saran}

1. Bank Indonesia harus lebih berperan dalam pengembangan pasar sekunder dengan cara menggunakan obligasi pemerintah sebagai instrumen moneter, sehingga obligasi pemerintah semakin likuid,

2. Proses kepemilikan dan penggantian SBI dengan obligasi pemerintah dalam pelaksanaannya tetap harus mempertimbangkan dampak terhadap suku bunga di pașar uang dan pencapaian target base money,

3. Untuk penggantian SBI sebagai alat instrumen moneter dengan dengan SUN ON diharapkan dilakukan secara bertahap sehingga dapat meredan gejolak kenakan suku bunga bila dibandingkan dengan penggantian secara sekaligus,

4. Timbulnya kewaj ban bagi pemerintah untuk membayar bunga, sebaiknya dapat dilakukan dengan menerbitkan surat berharga atau obligasi jangka pendek, mengingat pasar uang di indonesia masih mengacu pada instrumen jangka pendek,

5. Pemerintah mempunyai kewajiban untuk membayar bunga kepada $\mathrm{Bl}$, sehingga mempengaruhi perhitungan anggaran. Oleh karena itu diperlukan adanya kesepakatan yang tidak merugikan otoritas moneter dan fiskal. 


\section{Daftar Pustaka}

Bank Indonesia, Kajian Terhadap Penggunaan Obirgas! Pemerintah sebagai Salah Satu Allematif instrumen Kebijakan Monoter. 1999. 2005. Laporan Tahunan Sistem Pembayaran.

Budilaksono, Agung. Kajian Penggunaan Surat Utsng Negara (SUN) sebagar Instrumen Maneter yang Efeikfif dan Efisien, Direktorat Riset dan Ekonomi dan Kebijakan Moneter Bank Indonesia. 2004.

Dewanti, Wahyu. Surat Utang Negera (SUN) sebagai insirumen Moneter Impiementasi UU Perbendaheraan Negara, Drektorat Riset dan Ekonomi dan Kebijakan Moneter Bank Indonesia. 2004.
Herbudiningsh, Sinta Dewi, Laporan Tahunan Surat Vtang Negara 2005, Direktorat Pengelolaan Moneter Bank Indonesia, 2005.

Laksmono R, Didy, dkk, Penggunaan Obligasi sebagai Alternatif instrumen Kebijaksanaan Moneter dan Dampaknya terhadap Perkembangan Agregat Monefer dan Suku Bunga, Direktorat Riset dan Ekonomi dan Kebijakan Moneter Bank Indonesia. 2004.

Siamat, Dahlan, Manajemen Lembaga Keuangan, Kebijakan Moneter dan Perbankan, Lembaga Penerbit Fakultas Ekonomi Universitas Indonesia.

Undang-Undang No. 24 Tahun 2002 tentang Surat Utang Negars2005.

http:J/www.bankofenglan.co.uk

\title{
UCAPAN BELASUNGKAWA
}

\author{
Innalillahi Wainna Waihi Roji'un
}

Segenap Pengelola

Majalah Ilmiah WIDYA Kopertis Wilayah III

Menyampaikan Ucapan Belasungkawa

Atas meninggalnya

Drs. H. Sjukri Achadijalsjah bin Tjukup Datuk Sinarosati

(Suami dari Ibu Dra. Netty Herawaty, MM.

Sekretaris Kopertis Wilayah III/

Pembina Majalah Ilmiah WIDYA)

Meninggal pada tanggal 1 April 2009

Di Rumah Sakit Pertamina Pusat Jakarta pukul 18.51

Dikebumikan pada tanggal 2 April 2009

Di TPU Pondok Kelapa Jakarta Timur

Semoga Allah menerima semua amal ibadahnya dan Almarhum ditempatkan di sisiNya sebaik-baiknya.

Kepada keluarga yang ditinggalkan semoga diberikan

kesabaran dan kekuatan iman

Amin Ya RabbalAlamin. 